\title{
Usos y abusos del fuero militar entre los milicianos pardos de Santiago de Chile durante la segunda mitad del siglo XVIII: un aporte documental*
}

Hugo Contreras Cruces ${ }^{* *}$ hucontrerasc@yahoo.com Doctor en Historia por la Universidad de Chile.

\section{Presentación}

La apelación a fueros y privilegios era, probablemente, una de las opciones más recurridas por quienes se enfrentaban, de forma contradictoria o no, a las instituciones administrativas, judiciales o fiscales en la América monárquica. En tal sentido, las informaciones de méritos y servicios de los miembros de las huestes de conquista y posteriormente de los soldados de las fronteras septentrionales y meridionales, así como las de los eclesiásticos, particularmente las de los curas doctrineros que pugnaban por ascensos, premios o prebendas pueblan parte importante

\footnotetext{
* Esta contribución forma parte del proyecto de Núcleos Temáticos de Investigación (NTI) 2014 "Milicianos y soldados afrodescendientes en Chile, siglos XVIII y XIX. La lucha por el reconocimiento social y la libertad", de la Universidad Academia de Humanismo Cristiano.

** Académico de la Escuela de Historia de la Universidad Academia de Humanismo Cristiano. Miembro del Laboratorio de Historia Colonial de la Pontificia Universidad Católica de Chile.

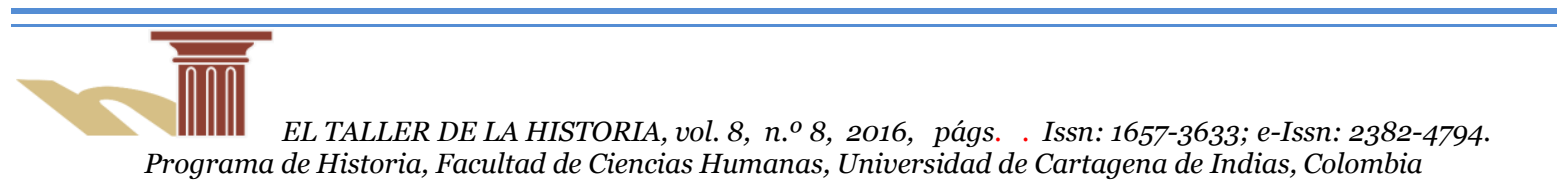


de los archivos españoles y latinoamericanos y, en su momento y aun hoy en día, se han constituido en un insumo de información gigantesco para la reconstrucción de los procesos políticos y sociales americanos, aunque menos de las representaciones que estos hombres dejaron de sí mismos y de otros. ${ }^{1}$ Algunos de estos "otros", nos referimos a los indios, eran continuos recurrentes de los llamados foros de justicia creados para ellos, precisamente apelando a al hecho de ser sujetos de privilegios por su condición de tales, lo que les permitía no solo presentar sus causas directamente ante las Reales Audiencias, sino también ser juzgados bajo regímenes de excepción, aunque ello no era válido en caso de que cometieran crímenes, pero sí para una serie de otras situaciones judiciales como era los delitos que atentaban contra su libertad, sus bienes o sus propias personas, así como aquellas situaciones derivadas de las sucesiones cacicales, pues no hay que olvidar que eran los indios y solo ellos los únicos que tenían derecho a constituir comunidades basadas en su origen, aun cuando éste podía discutirse, y derivado de ello a ser gobernados por jefes locales legitimados en principio por la pertenencia a un linaje de "señores naturales" y, más tarde, por la acción de la propia comunidad y refrendada por los tribunales, que a falta de herederos o en la eventualidad que los derechos de uno u otro postulante al cargo no fueran todo lo claros que la legislación esperaba, nombrar un cacique interino hasta resolver definitivamente el caso. ${ }^{2}$

No obstante lo anterior y considerando que la sociedad colonial latinoamericana se fue haciendo progresivamente más compleja social y racialmente y que, dentro de lo mismo, los españoles y sus descendientes así como los indios y los suyos no eran los únicos sujetos sociales que poblaban los territorios imperiales castellanos, aunque si eran quienes gozaban de un status legal particular, las llamadas "república de los españoles” y "república de los indios”, es que es válido preguntarse si era posible que las lógicas de apelación a fueros y privilegios tanto institucionales como personales eran posibles de encontrar en otros grupos sociales americanos y, particularmente, en aquellos de origen y desarrollo mezclado. Quienes per-

\footnotetext{
${ }^{1}$ En tal sentido véase la sección Gobierno del Archivo General de Indias en el cual se reúnen las diferentes Audiencias coloniales y el fondo Indiferente General. Todas ellas contienen un número importante de legajos que bajo la catalogación "Informaciones de oficio y parte" o "informaciones de oficio" concentran las probanzas de méritos y servicios de funcionarios, militares, eclesiásticos y algunos caciques indígenas.

${ }^{2}$ A modo de ejemplo véase los documentos contenidos en el fondo Real Audiencia del Archivo Nacional Histórico de Chile, donde se encuentra gran parte de las fuentes que dicen relación con los indios coloniales chilenos.
} 
tenecían a los grupos mestizos y de castas tenían pocas oportunidades de hacer valer sus méritos personales, a menos que lograran disfrazar sus colores y pasar como españoles o bien que lograran insertarse en algunas instituciones ligadas al ejercicio administrativo, eclesiástico o militar, pero aun esto era complejo y generalmente, en el caso de las dos primeras áreas, ocupaban puestos subalternos y de escasa notoriedad. En los ejércitos y tropas de presidio la posibilidad era teóricamente mayor, pero dependía tanto de donde estaban situados los contingentes militares como de las condiciones bélicas de la zona. Si es que había una guerra abierta u hostilidades recurrentes como en las fronteras de Chile durante el siglo XVII dichas posibilidades se acrecentaban, pues siempre era posible realizar algún acto considerado valiente e incluso heroico (aunque aquello estaba abierto a todos los militares), pero si su ejercicio castrense se resumía en esperar el ataque de algún enemigo en alguno de los presidios que la monarquía mantenía en lugares como Valdivia, El Callao, Cartagena de Indias o La Habana las opciones para destacar podían reducirse al mínimo.

No obstante lo anterior, la inserción en los cuerpos militares de la monarquía en el transcurso del siglo XVIII y sobre todo bajo el gobierno de Carlos III, se convirtió en una gran oportunidad para que los hombres de casta pudieran mostrar su lealtad a la corona, para que ella y sus funcionarios los visualizaran como sujetos a quienes se les podían entregar responsabilidades así como algunos fueros y privilegios en reconocimiento a sus crecientes servicios como milicianos, pero también como una forma de incentivar su buena conducta personal y grupal.3 En toda América, según lo ha ido planteando la historiografía preocupada de estos procesos, es posible detectar que será precisamente en el siglo XVIII cuando parte de los negros, mulatos y zambos libres y en particular aquellos que vivían en las ciudades coloniales y poseían oficios artesanales o se dedicaban al comercio, pugnaron por conseguir mayor bienestar material para ellos y sus familias; por insertarse en las insti-

\footnotetext{
3 El fuero militar para los sujetos de casta es frecuentemente mencionado por la historiografia que se ha preocupado de reconstituir la historia de los milicianos negros y afromestizos, sin embargo, el análisis de su uso y las consecuencias que se derivaban del mismo todavía es un tema que debe ser profundizado. Un análisis de esta institución para los cuerpos de castas en: Ben Vinson, Bearing armas for his majesty. The free-colored militia in colonial Mexico, Stanford, Stanford University Press, 2001, pp. 173-198; Joseph P. Sánchez, "African freemen and the fuero militar: a historical overview of the pardo and moreno militiamen in the late Spanish empire", en Colonial Latin American Historical Review vol. 3-2, Alburquerque, Universidad de Nuevo México, 1994, pp. 165-184.
} 
tuciones que estaban a su disposición, principalmente cofradías y compañías milicianas y por lograr una mejor inserción social, separándose en lo posible de la plebe, para intentar sumarse desde abajo a los sectores medios urbanos. 4

Ello tenía signos visibles, entre los que se contaban tanto las vestimentas de los cófrades y su desfile para las fiestas religiosas como los uniformes y las fornituras de los milicianos, pero también incluían los privilegios que estas inserciones institucionales les brindaban, que aunque menos visibles materialmente producían efectos mucho más importantes y cuyos beneficiarios estaban dispuestos a usarlos aun si ello revelaba las contradicciones que en su vida o en su discurso se manifestaban. En tal sentido, al enfrentarse a sus contrapartes en los foros de justicia, pero antes de ello, en lo que podían ser ciertas acciones significativas de su vida personal, las excepciones que les brindaba la milicia salían a relucir aun si ellas no eran realmente centrales para resolver una situación en particular. Ello, en alguna medida, decía relación con el peso específico que la pertenencia a estas instituciones había llevado a la vida de los milicianos de color, más aun si eran oficiales, lo que implicaba lograr sustentar los gravámenes que su inserción militar les planteaba, traducida en la compra de uniformes y armas, pero también en el hecho de destinar parte de su tiempo para entrenamientos, reuniones, presentaciones y eventuales movilizaciones fuera de sus lugares de habitación, como podían ser el puerto de Valparaíso o las fronteras de Concepción y Valdivia.

El uso y quizás el abuso de estos privilegios en situaciones alejadas de los contextos militares que los explicaban es lo que pretendemos mostrar con los documentos que presentamos en esta oportunidad. Se trata de cuatro expedientes judiciales en los que al menos uno de los litigantes es un mulato miliciano. De ellos, los tres primeros tienen carácter penal y se encuentran en el fondo Capitanía General del Archivo Nacional Histórico de Chile, lo que ya da un indicio del uso del fuero militar pues este repositorio documental reúne la documentación generada por la

\footnotetext{
4 Hugo Contreras Cruces, "Oficios, milicias y cofradías. Éxito económico, prestigio y redes sociales afromestizas en Santiago de Chile, 1780-1820", en Revista de historia social y de las mentalidades vol. 17-2, Santiago, Universidad de Santiago de Chile, 2013, pp. 43-74; Sergio Paolo Solano y Roicer Florez, “"Artilleros pardos y morenos artistas”: artesanos, raza, milicias y reconocimiento social en el Nuevo Reino de Granada, 1770-1812", en Historia Crítica n ${ }^{\circ}$. 48, Bogotá, Universidad de Los Andes, 2012, pp. 11-37; Jean-Paul Zúñiga, «Africains aux Antipodes. Armée et mobilité sociale dans le Chili colonial », en Carmen Bernand y Alessando Stella (coords), D'Esclaves a Soldats. Miliciens et soldats d'origine servile XIII ${ }^{e}-X X^{e}$ siècles, París, L'Harmattan, 2006), pp. 115-132; Francis Albert Cotta «Les compagnies de mulâtres et de noirs libertos. Mobilité sociale et offices militaires dans les Minas Gerais, Brésil XVIII" siècle », en Bernand y Stella (coords), D’Esclaves a Soldats, pp. 149-162.
} 
institución gubernamental chilena, entre ella los expedientes judiciales en que el gobernador fallaba como juez privativo, específicamente aquellos que involucraban a miembros del Real Ejército de la Frontera y a quienes formaban parte de las fuerzas milicianas que gozaban del privilegio ya significado, lo que tenía su primer antecedente en la real cédula dictada en Madrid el 12 de diciembre de 1608, lo que fue reiterado numerosas veces a lo largo de los siglos XVII y XVIII.5 Mientras tanto, el último de los procesos reproducidos se sustentó ante la Real Audiencia de Santiago de Chile, juzgado que según las disposiciones de la Pragmática sanción de 1776 y extendida a América dos años más tarde, debía fallar los casos de disenso matrimonial. En este caso, el fondo documental que cobija a este expediente es, como podría esperarse, el de Real Audiencia del mismo Archivo Nacional Histórico de Chile pero los argumentos respecto de la pertenencia miliciana del demandante, en esta oportunidad el tío del querellado, son centrales para situar al primero de ellos como un hombre de bien.

El primer documento que reproducimos nace de una querella interpuesta por un comerciante hispano-criollo, don Ignacio Francisco de Milán, contra su conocido y vecino, el bodegonero pardo Manuel Fernández, a quien Milán acusó de haberlo ofendido públicamente en el curso de una discusión que nació tanto de los roces personales entre ambos como de una deuda no pagada por Fernández a Milán, quien le había prestado algunos pesos precisamente por ser su vecino y un hombre con un paradero conocido y un trabajo fijo. Sin embargo, la disputa pareció salirse de curso y derivó, según el querellante, en expresiones que ofendieron tanto su posición socio-racial como su honor, pues Fernández lo asimiló a los hombres como él, es decir, a los mulatos. Ello trajo a colación el tema siempre sensible de la limpieza de sangre y lo que para los hispano-criollos era la ausencia de mala raza, cuestión compleja en América y que necesitaba de ser defendida pues la duda podía instalarse con facilidad. 6

5 Real cédula sobre que el gobernador de Chile como capitán general conozca de todos los delitos de los soldados, así en primera como en segunda instancia. Madrid, 12 de diciembre de 1608 . Archivo Nacional Histórico (Santiago, Chile) (ANH), Fondo Cabildo de Santiago, volumen 10, ff. 30 vta.-31.

${ }^{6}$ Sobre el honor y su gestión tanto cotidiana como documental en Chile véase: Verónica Undurraga Schüler, Los rostros del honor. Los rostros del honor. Normas culturales y estrategias de promoción social en Chile colonial, siglo XVIII, Santiago de Chile, Centro de Investigaciones Diego Barros Arana-Editorial Universitaria, 2012. 
El segundo expediente reproducido muestra con notable vivacidad como el goce del fuero militar era un elemento de gran presencia en la vida cotidiana de los milicianos mulatos. A partir de un incidente menor, que involucró a un hijo pequeño del maestro Tadeo Hidalgo, quien ofendió verbalmente a una pulpera asimismo de casta y que denunció el hecho ante el corregidor de la ciudad, Hidalgo fue citado a la presencia de esta autoridad para explicar lo sucedido. En vez de concurrir ante ella y a pesar de que salió de su casa para, supuestamente, ir a donde era requerido al pasar frente a cuerpo de guardia del palacio del gobernador aprovechó un descuido del alguacil que lo acompañaba e intempestivamente entró allí, los soldados por su parte cerraron filas tras él y al momento en que el alguacil lo reclamó uno de los guardias solo se limitó a expresarle: “...vuestra merced no se canse que esto es como sagrado..." 7 mientras que Hidalgo le enviaba un mensaje al corregidor expresándole que desde allí se comunicaría con su capitán y que luego de ello estaba dispuesto a seguir el proceso que eventualmente se le pudiera incoar.

En el tercer expediente nuevamente reproducimos un proceso por injurias, pero en esta oportunidad será un oficial mulato, el maestro sastre Ambrosio Guerrero quien se querellará contra un hispano-criollo al sentirse ofendido ante las palabras de éste. A raíz del cobro de una deuda que la abuela del ofensor mantenía con la cofradía de la que Guerrero era mayordomo, lo que muestra en otro ámbito institucional como los mulatos santiaguinos gestionaban su inserción social, se produjo un intercambio de palabras entre ambos sujetos lo que fue interpretado por Guerrero como una afrenta a su honor, reaccionando según las formas típicas en que un sujeto inserto en las configuraciones culturales de la época habría reaccionado, a menos que formara parte de los sectores populares, que parecían preferir el uso la violencia para resolver sus conflictos que el recurso a los tribunales, en lo que Undurraga ha denominado el ejercicio del honor agonal. ${ }^{8}$

La última fuente compilada en esta contribución la constituye una querella por disenso matrimonial que introdujo el cabo retirado de la compañía de granaderos Nicolás Escobar, por cierto un pardo, quien se oponía al matrimonio de su sobrino, a quien significó como español con una mujer que él consideraba claramente inferior a su joven pariente. Paradójicamente, en principio, dicha novia era afrodescendiente pero con un pasado genealógico-racial controvertible al menos para

\footnotetext{
7 ANH, Fondo Capitanía General (CG), volumen 309, f. 323 vta.

8 V. Undurraga, Los rostros del honor, p. 257 y ss.
} 
Escobar, pues era hija de una india y lo que llamó un "zambo atesado", personas a quienes los mulatos parecían despreciar o bien encontrar inferiores, como se puede ver en el juicio que sostuvieron para los mismos años el capitán Gregorio José de Arenas y el maestro indio Rafael Oré y que se ha reconstruido en otro artículo. ${ }^{9} \mathrm{Pe}-$ ro ello no era lo único, pues junto con resaltar la españolidad de su sobrino argumenta que su futura mujer era madre soltera de varios hijos de diferentes padres y que ejercía como vendedora ambulante en las calles de Santiago. Estos factores se sumaban para producir la inferioridad, pero es difícil determinar cuál de ellos era el o los más preponderantes a la hora de concebir al otro, en este caso a la mujer llamada Escolástica Ferreira. Ello abre interrogantes complejas, pero al mismo tiempo permite discutir como los sujetos construyen su auto-imagen y las de los otros, así como interrogarse respecto de los límites que podía tener la raza y los contextos en que estos se argumentan, que no dejan de tener contradicciones y no se ajustan necesariamente a una lógica o aun al llamado sentido común, sin embargo, eso hace a estos documentos profundamente humanos, pues la contradicción parece ser parte integrante del ejercicio vital.

En suma, la documentación que presentamos abre puertas al conocimiento histórico de los sujetos populares y en proceso de ascenso social de la segunda mitad del siglo XVIII y más aún genera interrogantes en diferentes planos, los que van desde las prácticas judiciales y las formas en que las personas, en esta caso algunos milicianos mulatos de Santiago de Chile, se relacionaban con las instituciones de justicia y en ese sentido, como estos eran capaces de usar los fueros y privilegios que su condición miliciana les daba - incluso extremando los alcances de los mismos - para sacar ventaja de las situaciones que los aquejaban, sobre todo si ellos eran los afectados, como bien lo demuestran las acciones de Tadeo Hidalgo o, en el otro lado de la vereda, si estos podían otorgarles algún status distintivo frente a la contraparte, pero particularmente respecto de los administradores del poder colonial, que eran los verdaderos objetivos de sus actuaciones públicas, al menos en sus querellas civiles y, por supuesto, en el ejercicio militar.

\footnotetext{
9 Hugo Contreras Cruces, "Las milicias de pardos y morenos libres de Santiago de Chile en el Siglo XVIII, 1760-180o", en Cuadernos de Historia $\mathrm{n}^{\circ}$ 25, Santiago de Chile, Universidad de Chile, 2006, pp. 112-115.
} 


\section{Bibliografía}

Contreras Cruces, Hugo, “Oficios, milicias y cofradías. Éxito económico, prestigio y redes sociales afromestizas en Santiago de Chile, 1780-1820”, en Revista de historia social y de las mentalidades vol. 17-2, Santiago, Universidad de Santiago de Chile, 2013, pp. 43-74.

Contreras Cruces, Hugo, "Las milicias de pardos y morenos libres de Santiago de Chile en el Siglo XVIII, 1760-180o”, en Cuadernos de Historia $\mathrm{n}^{0}{ }_{25}$, Santiago de Chile, Universidad de Chile, 2006, pp. 93-117.

Cotta, Francis Albert, «Les compagnies de mulâtres et de noirs libertos. Mobilité sociale et offices militaires dans les Minas Gerais, Brésil XVIII ${ }^{\mathrm{e}}$ siècle ", Carmen Bernand y Alessandro Stella (coords), D'Esclaves a Soldats. Miliciens et soldats d'origine servile XIII ${ }^{e}-X X^{e}$ siècles, París, L'Harmattan, 2006), pp. 149-162.

Sánchez, Joseph P., "African freemen and the fuero militar: a historical overview of the pardo and moreno militiamen in the late Spanish empire", en Colonial Latin American Historical Review vol. 3-2, Albuquerque, Universidad de Nuevo México, 1994, pp. 165-184.

Solano Sergio Paolo y Florez, Roicer, ““Artilleros pardos y morenos artistas”: artesanos, raza, milicias y reconocimiento social en el Nuevo Reino de Granada, 1770-1812”, en Historia Crítica nº . 48, Bogotá, Universidad de Los Andes, 2012, pp. 11-37.

Undurraga Schüler, Verónica, Los rostros del honor. Los rostros del honor. Normas culturales y estrategias de promoción social en Chile colonial, siglo XVIII, Santiago de Chile, Centro de Investigaciones Diego Barros Arana-Editorial Universitaria, 2012.

Vinson, Ben, Bearing arms for his majesty. The free-colored militia in colonial Mexico, Stanford, Stanford University Press, 2001.

Zúñiga, Jean-Paul, «Africains aux Antipodes. Armée et mobilité sociale dans le Chili colonial », en Carmen Bernand y Alessando Stella (coords), D'Esclaves a Soldats. Miliciens et soldats d'origine servile XIII ${ }^{-}-X X^{e}$ siècles, París, L’Harmattan, 2006, pp. 115132 


\title{
Don Ignacio Francisco de Milán. Autos por injurias contra Manuel Fer- nández, pardo, soldado de la Compañía de Granaderos. ${ }^{10}$ Santiago, 1767.
}

\author{
Querella por injurias de don Ignacio Milán contra Manuel Fernández. Santiago, 9 \\ de febrero de 1767.
}

"Don Ygnacio Francisco de Milan en la mejor manera que haya lugar en derecho paresco ante vuestra merced y me querello sivil, y criminalmente contra Manuel Fernandes de casta pardo; y refiriendo el casso, que justifica mi querella Digo que oy que se cuentan seis del corriente como a las onze del dia viniendo de cierta diligencia alle al muchacho que me sirve a la puerta del bodegon del dicho Manuel y reprehendiendolo porque no estava en la de mi tienda, llegó a este tiempo un conosido, que oyendome preguntó que tenia, a que respondi, que estava corrigiendo al muchacho por haverse ido a sentar en la puerta de este hombre quien porque puse demanda contra el ante vuestra merced por unos pesos que me deve, sin atender al devido respeto que merese la persona y representacion de vuestra merced me oprobió en varias palabras contra mi honor y calidad, y como estuviese yendo se vino a la puerta de mi tienda que esta en frente de la de su bodegon, diciendo que yo era un mulato, y que conose a mi padre que es un mulato panadero, que quando llegase el casso havia de hazer que marchase con el, y los de su clase profiriendo esto en vozes altas una y otra vez en medio de la calle, por cuia causa salieron escandalizadas a las puertas de sus casas varias personas, que por mis honrados prosederes tienen echo concepto de las obligaciones que me asisten, como vuestra merced se servira reconoser por los documentos que demuestro en devida forma para que se me debuelban, y a mayor abundamiento siendo necesario protexto justificarlo con testigos de distincion a los quales oprobios no respondi otra cosa que decir a las personas, que se hallavan presentes me sirviesen de testigos para probar las libertades, injurias, probocaciones, y desonras en que dicho bodegonero me trataba; a que repitto, que se afirmava en lo que desia, y que lo mismo havia dicho en presencia de vuestra merced en cuyos terminos por dicho instrumento que llevo presentados conosera vuestra merced la noblesa, que me asiste, y el crimen que ha cometido dicho bodegonero en haver proferido las abominaciones expresadas contra mi creditto, y buena opinion, pues aunque no fuera como soy de ylustre nacimiento siempre era delito, porque mirava a probocar a quien no dava ocacion, $y$

\footnotetext{
10 ANH CG, volumen 300, ff. 323-330 vta. Las transcripciones presentadas en esta contribución se han hecho respetando la ortografía y redacción de los originales; se han desplegado las abreviaturas y solo para efectos de una mejor comprensión se han incorporado signos de puntuación allí donde estos estaban ausentes, por ejemplo en los finales de párrafo, conservándose los que venían en los documentos.
} 
aun quando la diese no le era licito proseder ni de obra, ni de palabra, sino ocurrir a la real justicia, de cuyo echo sino hubiera sido conmigo, que considerando la justificacion de vuestra merced y que ha de castigar estos a[tre]vimientos para que en adelante proseda con la devida moderacion no hay duda huviera sucedido una desgracia.

Y assi respecto de constar a vuestra merced que el dicho Manuel Fernandes es muy atrevido por los desaogos que me dijo en la presencia de vuestra merced que por careser del conosimiento que le administraran los ynstrumentos demostrados, no haria concepto formal del delito que comento, sin duda persuadiendose a que serian ciertas las denigraciones que prorrumpio ocurro a la justificacion de vuestra merced para que se sirva mandar se me resiva ynformacion al tenor de este e[scrito] de querella, y dada en la parte que baste despachando mandamiento de prission, y embargo de bienes contra la persona del dicho bodegonero Manuel Fernandes que presso, y tomada su confession protexto poner la acusacion en forma, para que se le imponga por su desacato el castigo correspondiente en cuia at[encion.]

A Vuestra merced pido y suplico que en virttud de lo expresado en este [escrito] de querella se sirva mandar en todo como [lle]vo pedido, y juro a Dios nuestro señor y esta señal de cruz + no prosedo de malicia sino en justicia que pido costas etca .

\section{Don Ygnacio Francisco de Milan”}

Decreto. Santiago, 9 de febrero de 1767.

"Por manifestados los ynstrumentos y se ad[mi]te esta querella en quanto ha lugar de derecho y a[com]pañe la ynformacion que ofrese y fecho autos.

Santelices

Proveyo y firmo el decreto de suso el señor maestre de campo don Ramon de Santelices alcalde ordinario desta ciudad de Santiago de Chille en nueve dias del mes de febrero de mil setesientos sesenta y ciete años años de que doy fee $=$

Ante mi

Santiago de Santivañez

Escribano publico y de provincia"

Declaración de don Ramón Domínguez. Santiago, 9 de febrero de 1767.

"En dicho dia su merced para la ynformazion ofresida hizo comparezer ante si a don Ramon Dominguez residente en esta ciudad y natural de la de Sevilla en los 
reinos de España, de quien por ante mi el presente escrivano fue rezivido juramento por Dios nuestro señor y una señal de cruz en forma devida de derecho so cargo del qual prometio decir verdad en lo que supiera y le fuere preguntado y siendolo al thenor del escrito presentado dixo; que haviendo llegado el sabado siete del corriente como a las diez oras de la mañana a la tienda que tiene la parte que le presenta en la calle de las Matadas ${ }^{11}$ hallo mui aflixido, y abochornado a dicho don $\mathrm{Yg}$ nacio Milan, quien haviendole preguntado el declarante que tenia le dixo, que por hazer bien a un mozo que vive frente de la tienda, avilitando con unos reales para que buscase su vida, y no haviendo cumplido con su paga, se havia presentado contra el, para su satisfaccion, y que de resultas desto se havia su deudor desahogado con decirle mil afrentosos motes, y agravios, poniendolo como un trapo, lo que sentia tanto, que no savia que hazer para restaurar el antiguo honor que tenia heredado de sus antepasados, como lo justificaba los ynstrumentos que me enseñó, y le[yo] un testimonio de ynformazion dado por su padre don Joseph de Milan en la ciudad de Milan digo de Lima, y que viendolo apasionado, aunque con bastante causa lo procuro sosegar; y que a las razones, que le estaba diziendo, algo altas dicho don Ygnacio al que declara, y oyendolas la parte contraria se vino a la tienda de dicho don Ygnacio, que no tenia que decir nada ya que savia lo que le havia dicho delante del mismo señor maestre de campo porque era mui cierto, y le co[no]cia que era hijo de un mulato panadero de Lima y otras muchas palabras provocativas a lo que solo respondio dicho don Ygnacio, que se lo havia de hazer bueno, por lo que ne procuro por testigo, e igualmente cito a una muger que a las vozes avia salio a la calle, y que esto es lo que puede decir en el asumpto, y la verdad so cargo del juramento que fecho tiene en que se afirmo, y ratifico siendole leida esta su declarazion, y la firmo con dicho señor maestre de campo diziendo era de edad de veinte y quatro años de que doy fee entre renglones $=$ Lima $=$ vale $=$

Santelices

Ramon Dominguez ante mi

Santiago de Santivañez

Escribano Publico y de Provincia"

Declaración de doña María Josefa Jiménez. Santiago, 9 de febrero de 1767.

"En dicho dia la parte para la dicha ynformazion presento por testigo a doña Maria Josepha Ximenes a quien por comision verval de el señor maestre de campo don

${ }^{11}$ Corresponde a la actual calle Santa Rosa, situada a una cuadra hacia el oriente del convento de San Francisco, que comienza en la vereda sur de la Avenida Bernardo O'Higgins y se proyecta hacia el sur de la ciudad de Santiago de Chile. 
Ramon de Santelises alcalde ordinario y jues desta causa paso a tomar su declarasion a la calle de las Matadas, y estando en las casas de su morada le resivi juramento que hiso por Dios nuestro señor y una señal de cruz segun derecho so cargo del qual prometio desir verdad de lo que supiere y le fuere preguntado, y siendolo al thenor del escrito de querella dijo: que lo que unicamente puede declarar es, que el dia savado en que tubo don Ygnacio Milan su disgusto con el bodegonero que esta enfrente de su tienda salio por casualidad a la calle a tiempo que el dicho don Ygnacio Milan estava en la calle, y le dijo a la declarante; no oie usted lo que me dise este hombre de que soi un mulato usted me ha de servir de testigo a que respondio la que declara no he oido nada, y se le a dicho eso a echo mui mal de desir a un hombre en la calle publica semejantes palabras que con esto se dentro a su casa sin saver ni entender otra cosa. Y que esta esa la verdad so cargo de su juramento en que se afirmo, y rattifico siendole leyda esta su declarasion, que las generales de la ley no le tocan y es mayor de treinta años y no firmo porque dijo no saver de que doy fee $=$

ante mi

Santiago de Santivañez

Escribano Publico y de Provincia"

Fe del escribano. Santiago, 9 de febrero de 1767.

"Doi fee que con la misma comision verval hise compareser ante mi a Maria de la Cruz parda [li]bre, y sin envargo de haverle resivido juramento y haverle echo varias preguntas aregladas al escrito de querella para que declarase dijo que no savia nada de oidas ni de otra forma con lo que di parte a don Ygnacio Milan y dijo que se le tomase declaraz[ion] a otra muger que esta en casa de Francisco Morales tambien llamada Maria de la Cruz y exsaminada respondio que no savia nada de que $\mathrm{ta}[\mathrm{m}]$ bien di parte al dicho don Ygnacio para que hisiese su diligencia de que asimismo doy fee $=$

\section{Santivañez"}

Fe del escribano. Santiago, 10 de febrero de 1767.

"Doi fee que oi dies de febrero de mil setesientos sesenta y [siete] a pedimento de la parte de don Ygnacio Milan mando [el] señor jues desta causa compareser en su presencia [a] dicha Maria de la Cruz parda libre y a otra muger [que] dijo bivia en un quarto de doña Maria Garate las qua[les] exsaminadas con la forma al derecho nesesaria resp[on]dieron no saver nada de que asimismo doy fee $=$ 
Declaración de Juan Evangelista Sirena, barbero. Santiago, 13 de febrero de 1767.

"En la ciudad de Santtiago de Chille en trese dias del mes de febrero de mil settecientos sesenta y ciete años la parte para la dicha ynformazion presento por testigo [a] Juan Evangelista Cirena de quien fue resivido juramento que lo hizo por Dios nuestro señor y una señal de crus segun derecho so cargo de el qual prometio desir verdad de lo que supiere y le fuere preguntado y siendolo al thenor del escrito de querella dijo que lo que unicamente puede declarar es que estando este testigo aora tres dias en su tienda de barveria afeitando como concurriesen alli barias personas mientras estava asiendo una varva enpeso a contar uno de los que estavan en dicha tienda que le havian contado, como don Ygnacio Milan havia tenido palabras con un Manuel Fernandes que tiene bodegon enfrente de su tienda y que el caso havia pasado en esta forma = que el muchacho que sirve a dicho Milan se paso al bodegon del referido Manuel Fernandes, y a poco tiempo lo llamó dicho Milan disiendole quittate de ai muchacho ven aca no estes entre la canalla que mañana querras ser lo mismo que desto havia resultado que el bodegonero le dijese al referido Milan que el seria el canalla pues hera hijo de un mulato panadero de Lima que esto fue lo que oió, y no puede desir a quien por que no puso ate[cion] en el sugeto que lo desia ni volvió la cara porque a la sason se hallava afeitando como lleva dicho que el sugeto que conto esto en su tienda tanpoco dijo a quien lo havia oido y que esta es la verdad so cargo de su juramento en que se afirmo y ratifico siendole leida se declarazion que las generales de la ley no le tocan y es de edad de veinte años y la firmo con su merced de que doy fee $=$

Santelises

Juan Evangelista Sirena

ante mi

Santiago de Santivañez

Escribano Publico y de Provincia”

Declaración de Juana Villegas. Santiago, 14 de febrero de 1767.

"En la ciudad de Santiago de Chille en catorse dias del mes de febre[ro de] mil setesientos sesenta y ciete años la parte para la dicha ynfor[macion] presento por testigo a Juana Villegas muger española a quien $\mathrm{f}[\mathrm{ue}]$ recivido juramento que lo hiso por Dios nuestro señor y una señal de cruz [se]gun derecho so cargo de el qual prometio desir verdad de lo que supie[re] y le fuere preguntado y siendolo al thenor del escrito de querella [de] lo que puede declarar es que el dia savado de la semana $\mathrm{p}$ [asa]da fue a comprar medio rreal de azucar a la tienda de don Ygna[cio] Millan a 
tienpo que estava riñendo a su muchacho disiendole [por]que se iba a meter al bodegon de enfrente que sino savia que est[aba] mal con aquel hombre porque le havia puesto demanda co[gien]dole ante el señor alcalde: que estando en esto llego un om[bre] Domingues que disen es escriviente, y le pregunto a Milan por que estava tan abochornado y le respondio que estava cor[ri]jiendo a su muchacho porque se iva a meter al bodegon [de] enfrente, y ablar con aquel hombre que en presencia de dicho [al]calde le havia dicho que tanbien viere seria como el pero mejor y que como dicho bodegonero oyese estas palabras se fue [pa]ra la tienda de dicho don $\mathrm{Yg}$ nacio Milan y delante del dicho Domi[ngues] le dijo que si lo havia dicho y lo conosia mui bien que era [un] perro mulato hijo de un mulato panadero que entonzes [dijo] Milan con que ser mulato y saliendo para afuera de la [tienda] dijo a algunas personas que vio paradas que le sirviesen [de] testigos con lo que se fue este testigo sin oir ni ver mas n[i com]prar la asucar porque vio a dicho Milan tan enojado $\mathrm{qu}[\mathrm{e}]$ es lo que save y la verdad so cargo de su juramento en que se afir[mo] y ratifico siendole leida su declarasion que las generales de [la ley] no le tocan y es de edad de veinte y cinco años y no fir[mo] por no saver firmolo su merced de que doy fee $=$

Santelices

antte mi

Santiago de Santivañez

Escribano Publico y de Provincia"

Decreto. Santiago, 14 de febrero de 1767.

"Autos y vistos: Por lo que de la sumaria resulta contra Manuel Fernandez se despache mandamiento de prision y emvargo contra su persona y bienes en forma y conforme a derecho $=$

Santelices

Proveyo y firmo el decreto de suso el señor maestre de campo don Ramon de Santtelices alcalde ordinario desta ciudad de Santtiago de Chille en catorse dias del mes de febrero de mil setezientos sesenta y ciete años de que doy fee $=$

Despachado"

Santivañez

Decreto. Santiago, 16 de febrero de 1767.

"Respecto de tenerse noticia, que Man[uel] Fernandes, es soldado de la Compañia de Granaderos, se suspenda el mandamiento [de] pricion y embargo contra su per- 
sona ya [des]pachado, y don Ygnacio Milan huse de su derecho en el tribunal que le com[pete]

\section{Santelices"}

Proveyo, y firmo el decreto de suso el señor maestre de camp[o don] Ramon de Santtelizes alcalde ordinario desta c[iudad] de Santtiago de Chille en dies y seis dias del mes de febrero de mil setezientos sesenta y ciete (sic) años de que doy fee =

Santivañez"

Notificación. Santiago, 16 de febrero de 1767.

"en dicho dia nottifique el decreto de suso a d[on] Ygnacio Milan de que doy fee = Santivañez"

Decreto. Santiago, 17 de febrero de 1767.

“Santiago y febrero 17 de 1767

Autos $=$

\section{Doctor Lopez"}

Decreto. Santiago, 18 de febrero de 1767.

"Santtiago y febrero 18 de 1767

Despachese mandamiento de pricion; y embargo [con]ttra la persona, y bienes del artillero Man[uel] fernandez en forma, y conforme a derecho

\section{Ugartte"}

Doctor Lopez

Orden del corregidor de Santiago don Luis Manuel de Zañartu al alguacil mayor para que aprese y embargue los bienes a Manuel Fernández.12 Santiago, 19 de febrero de 1767.

${ }^{12}$ ANH CG, volumen 3, f. 521. A pesar de que pertenece al mismo expediente este documento se encuentra en otra ubicación del mismo fondo archivístico. En esta oportunidad, junto con citar la referencia documental, lo hemos incluido en el proceso en el lugar que por su fecha le corresponde. 
"Don Luis Manuel de Zañartu corregidor justicia mayor de esta ciudad lugarteniente de capitan general, y por enfermedad del Muy Ylustre Señor Presidente Gobernador y Capitan General de este Reino subaltterno de el etc $=$

Por el presentte el alguacil mayor, o qualesquier de sus lugar thenientes travara execucion, y embargo en la persona, y bienes del artillero Manuel Fernandez pardo poniendolo en la carcel publica de esta ciudad, y sus bienes a cargo del deposittario general de esta cortte que otorgue depositto en forma, y conforme a derecho. Por quanto por decretto por mi proveydo asi lo tengo mandado fecho en Santtiago de chile en dies, y nuebe de febrero de mil setecientos sesentta y siette años =

\section{Luis Manuel Zañartu}

Por mandado del señor subalterno

Juan Geronimo de Ugartte

Secretario Mayor de Govierno"

Don Ignacio Francisco de Milán al corregidor de Santiago don Manuel de Zañartu. Santiago, 23 de febrero de 1767.

\section{"Señor Correxidor}

Don Ygnacio Francisco de Milan en los autos criminales, que sigo contra Manuel Fernandes de casta pardo bodegonero por los oprobios, e injurias con que me intentó afrentar en presencia del maestre de campo don Ramon Santelizes, que renobo a la puerta de mi tienda con gran probocacion, notable escandalo del vezindario, y descredito de mis honrados prozederes, y acreditada nobleza, y lo demas deducido, digo, que haviendo justificado lo referido ante dicho alcalde ordinario libró mandamiento de prission, y embargo de bienes y por ser artillero no se executo, hasta que ocurri a vuestra merced que se sirvio en meritos de la causa de llevar a devida execucion lo mandado por dicho maestre de campo; y respecto de que en su presencia me oprobio quasi con las mismas razones, que en mi tienda por que le demande treinta, y siete pesos que me debe; Hallandose presso en esta real carcel, antes que se proseda a tomarle su confession conviene a mi derecho que el dicho maestre de campo don Ramon Santelizes informe como es cierto que estando poniendo la demanda de dichos pesos con que tiene en parte avilitado su bodegon, prorrumpio diciendo; que piensa ser mejor que yo? ¿Que le parese, que no lo conosco? Yo hare que marche en mi compañia, y exprese su merced el atrevimiento y 
audacia con que profirio estas razones, para que se tenga presente al tiempo de tomarle su confession; por lo qual.

A vuestra merced suplico se sirva mandarlo assi por ser justicia costas etc.

Otro si a vuestra merced pido, y suplico que para que se venga en mas pleno conocimiento de la demasiada osadia del dicho Manuel Fernandes se sirva vuestra merced mandar que Gregorio Briseño, que le puso demanda ante dicho maestre de campo don Ramon Santelizes por un costal de grasa que le compró en suposicion de traerle su importe puntualmente y segun reconocio no tenia intencion de pagarle declare bajo de juramento como es verdad, que haviendolo embiado a llamar dicho maestre de campo, tuvo desverguensa, y atrevimiento de responder: digale al alcalde, que [no] quiero ir, y despues de haberse quedado suspenso el expresado Briseño sin duda ponderando tan demasiado [ar]rojo, y desacato le preguntó: como le digo que no quiere ir [a lo] que repitio: si, con lo que se fue, y como reparó a poca dista[n]cia, que serró su bodegon, y se encaminó tras el, luego qu[e] llegó Gregorio a la presencia de dicho maestre de campo, ocultó [dicho] delito de Manuel Fernandes diciendo: ya viene. Cuia declaras[ion] se servira vuestra merced assi mismo tener presente al tiempo de tom[ar]le su confession a la que protexto estar solo en lo favora[ble] que es justicia ut supra

Otro si digo, que haviendo tenido noticia Manuel Fernandes de[l] mandamiento librado por vuestra merced presentó escrito por cuy[a] causa parese no se ha executado plenamente faltando por actuar el requisito no menos principal, y assi se $\mathrm{h}[\mathrm{a}]$ de servir vuestra merced mandar se me de traslado del para en su vista deducir lo que convenga a mi derecho, por lo que A vuestra merced suplico assi lo provea, y mande, justicia ut supra.

Ygnacio Francisco de Milan”

Decreto. Santiago, 23 de febrero de 1767.

"Santiago y febrero 23 de 1767

En lo principal ynforme el maestre de campo don Ramon de Santtelizes alcalde ordinario de esta ciudad, al primer otrosi, y al segundo, se guarde lo proveydo =

\section{Ugarte"}

Doctor Lopez

Notificación. Santiago, 23 de febrero de 1767. 
"En dicho dia hise saver el decreto de la buelta al maestre de campo don Ramon de Santelises alcalde hordinario de esta ciudad de que doi fee $=$

$$
\text { Sandobal" }
$$

El maestre de campo don Ramón de Santelices al corregidor de Santiago don Manuel de Zañartu. Santiago, 25 de febrero de 1767.

\section{“Señor Subalterno}

El maestre de campo don Ramon de Santelises alcalde ordinario de esta ciudad en cumplimiento del decreto de enfrentte: dise, que haviendo ocurrido a su jusgado don Ygnacio Milan poniendo demanda contra Manuel Fernandes: estando ambos alegando le dixo dicho Milan a Fernandes, que hera un pardo, y este le repitio la misma rason: que es quanto tiene que ynformar en el asumpto: Santiago, y febrero veintte, y sinco de 67 .

Ramon de Santelices"

Don Ignacio Francisco de Milán al corregidor de Santiago don Manuel de Zañartu. Santiago, febrero de 1767.

\section{"Señor Correxidor}

Don Ygnacio Francisco de Milan en la mejor forma que haya lugar en derecho paresco ante vuestra merced y digo que por ciertos atrevimientos que tuvo conmigo Manuel Fernandes en presencia del maestre de campo don Ramon Santelizes, los que despues reproduxo a la puerta de mi tienda con notable escandalo por las probocaciones, vituperios, y ultraxes con que me oprobio, suficiente el menor de ellos a ocacionar una desgracia, me querelle ante dicho jues civil, y criminalmente ofreciendo informacion de lo referido, que dada en terminos legales, libró mandamiento de prission, y embargo de bienes contra el dicho bodegonero Manuel Fernandes, y iendo a actuarlo se tuvo noticia de que es granadero, y por esta motibo toca el conosimiento de la causa a la Capitania General y respecto de estar plenamente justificado su delito, y despachado el mandamiento como consta de dicha causa criminal, que presento con la solemnidad necesaria; por quanto dicho alcalde ordinario en conformidad de lo referido proveyo el decreto de fojas mandando use de mi derecho donde me convenga; ocurro a la rectitud, y justificacion de vuestra merced a quien pertenese el conosimiento de las causas de esta naturaleza para que se sirva mandar corra el mandamiento de prission, y embargo de bienes del dicho Manuel Fernandes expedido por el referido maestre de campo segun y como en el se expresa; y para que pudiera oponerse algun reparo por la razon expresada, de nuevo me querello civil y criminalmente contra el dicho [Manuel] Fernandes sobre que re- 
produsgo el sitado esc[rito] y querella para que la dicha causa y querella en $\mathrm{m}$ [erito] de [lo en] ella mandado tenga cumplido efecto, en cu[ya] atencion A vuestra merced suplico que atendiendo a lo expresado se sirva ma[n]dar en todo como llevo pedido por ser de just[icia] juro lo necesario en derecho costas etc.

Don Ygnacio Francisco de Milan” 
Expediente sobre la prisión impuesta al maestro Tadeo Hidalgo. ${ }^{13}$ Santiago, 1775 .

"Sobre pricion del maestro Thadeo Hidalgo

María Figueroa, esposa del maestro Tadeo Hidalgo, al gobernador de Chile. Santiago, 24 de mayo de 1775 .

"Muy Ylustre Señor Presidente

Maria Figueroa muger lexitima del maestro Thadeo Idalgo soldado de la conpañia de artilleros puesta a los pies de vuestra señoria con el mas sumiso rendimiento conforme a derecho. Digo; que el dicho mi marido se alla preso en el quartel de dragones siendo la causa de su pricion; el que con el motivo de haver criado la vesina que a puesto la querella una muchacha tubieron siertas boses con un hijo mio pequeño de lo que tomandose en si la causa cojio y despues de haverle dicho quanto se le antojo al expresado mi yjo, paso a la tienda de mi marido, y la ultrajo con barios dicterios e injurias provocatibas tocandole en su credito y honor tanto, y en tanto estremo que no pudiendo de otro modo contenerla cojio, y sin deliverado animo a vista de su gran probocacion, le toco con la mano buelta en la boca sin mas merito que este se fue de alli la dicha Francisca a quejarse a vuestro correxidor a quien le depuso el que dicho mi marido havia dicho que pusiese ante el su querella con otros falsos testimonios que como enconada le levanto nacido tambien este encono el que sobre un año a que le esta provocando lo que a tolerado mirando el respeto de vuestra señoria y respecto de que esta lebisima causa que no es otra la que a contraido la dicha Francisca con su tenasidad y malos prosedimientos an dado merito a la prision del dicho mi marido como estoy pronta a justificarlo hallandome por lo presente desanparada y con familia que mantener no teniendo otro aucilio que del trabajo de dicho mi marido ocurro a la piedad de vuestra señoria para que atendiendo al leve delito motivado de la causa de la dicha Fransisca persona bil, y pulpera por tanto.

A Vuestra Señoria pido y suplico que en vista de las rasones expuestas que estoy pronta desde luego en caso nesesario a justificarlas se cirva darle soltura de la pricion en que se alla el dicho maestro Thadeo Idalgo mi marido mersed que con justicia espero recibir de la piedad y benignidad de Vuestra Señoria y juro a Dios y a esta señal de crus + que es sierta mi rrelacion, y berdadera y que no prosedo de malicia, y en lo nesesario.

${ }_{13}$ ANH CG, volumen 309, ff. 320-324. 


\section{Maria Figera”}

Decreto. Santiago, 24 de mayo de 1775.

"Santtiago 24 de mayo de 1775

Ynforme el corregidor de esta ciudad $=$

Hay una firma Doctor Lopez

Borquez"

Informe del corregidor de Santiago don Luis Manuel de Zañartu. Santiago, 24 de mayo de 1775 .

“Muy Ylustre Señor Presidente

El corregidor de esta ciudad, cumpliendo con el superior decreto de la buelta, para que informe con vista del pedimento que hace el artillero Thadeo Ydalgo dize. Que en el acto en que hizo presente a vuestra señoria la falta de respecto, con que havia tratado dicho artillero el empleo de correxidor, diciendo a Francisca Quiñones, que las bofetadas que le havia dado se los quitase el correxidor mando vuestra señoria se tomasen las declaraciones de esto, y lo demas, que dio merito para que le huviese llamado comparecer ante si para oyrle en justicia, y en cumplimiento de dicha orden, y pasado oficio correspondiente para ello al ayudante mayor don Blas Gonzalez tomó a la citada Francisca Quiñones, y al ayudante Toribio Leyva las declaraciones que constan por los documentos que paso a manos de vuestra señoria conforme en todo a lo que deve ynformar el corregidor sobre la sujeta materia a que se remite, para que vuestra señoria determine lo que tuviere por combeniente. Santiago, y mayo 24 de 1775 .

\section{Luis de Zañartu”}

Decreto. Santiago, 26 de mayo de 1775.

"Santiago y mayo 26 de 1775

Pasese este expediente al señor Auditor de guerra

Jauregui

Doctor Lopez

Borquez" 
Declaración de Francisca Quiñones, pulpera. Santiago, 22 de mayo de 1775. [Al margen: "Declarazion de Francisca Quiñones"]

En la ciudad de Santiago de Chile en veinte y dos dias del mes de maio de mil setezientos setenta y cinco años. Yo don Blas Gonzalez theniente de cavalleria de la asamblea que hago las funziones de aiudante de la plaza de orden del señor presidente governador y capitan general de este reino don Agustin Jauregui mariscal de campo de los reales exercitos etc ${ }^{\text {a }}$. Hize comparezer ante mi en las casas de mi alojamiento a Francisca Quiñones, bodegonera para tomarle declarasion sobre lo que acaecio entre la dicha y el miliciano mulato Thadeo Ydalgo de la compañia de usares de esta capital preso en el quartel de dragones'4; y despues de haverle tomado el juramento acostumbrado para que dijesse la verdad de lo suzedido entre los susodichos prometio de decirla so cargo del dicho juramento =

Preguntada que confiesse y diga todo lo acaecido con el mencionado Ydalgo, para venir en conocimiento del delito de este $=$ Responde que viniendo de La Merced para lo de su patron don Pedro del Villar advirtio que venia detras de la declarante un niño del dicho miliciano ultrajandole con varias desberguenzas de que le hechaba agua al vino y que era una usurera etc ${ }^{\mathrm{a}}$., a que le respondio la declarante aora la vereis perro como se lo digo a tu padre, y que haviendo ydo a la tienda de este le conto los atrebimientos que su hijo havia tenido con ella y la satisfaccion que le dio, fue decirle quitate de ai canalla, marchate etc ${ }^{a}$., a que la replico la declarante diciendole buena crianza le da a su hijo, advierta vuestra merced que no es afrenta ser pulpera, tambien lo ha sido su mujer de vuestra merced de mi mismo patron, y solo por esto cargo contra la declarante y le dio tres bofetadas, con cuio ultraje viendose la que declara corrida le dijo aora boy a lo del correxidor para que me haga justicia a que respondio Idalgo vete que las bofetadas nadie te las ha de quitar i dile al correxidor que te las quite; y haviendose ido a ponerle la querella sobre lo sucedido lo encontro en lo de don Paulino Trabi y contandole todo por extenso le mando a un aiudante que fuesse a su cassa y que lo llevasse a la casa donde estava dicho correxidor para hacerle el cargo correspondiente y que la declarante porque no savia el aiudante la casa le acompaño hasta la del dicho Idalgo, a quien le dio la orden que su correxidor le havia prebenido; y respondiendo aquel que le dijesse al señor correxidor que mañana iria que ya sabia para lo que era y que a su capitan le havia dado parte de todo; a esto le replico el aiudante vuestra merced venga aora

\footnotetext{
14 Debiese decir Artilleros. La compañía de Húsares, que asimismo existía en Santiago para la época, reunía a los negros y zambos de la ciudad, sin embargo, solo sus oficiales y sargentos gozaban de fuero militar. Los artilleros en cambio eran sujetos de este privilegio desde los soldados rasos. Respecto de la estructura de las fuerzas de casta en Santiago: H. Contreras, Las milicias..., pp. 93-117.
} 
que assi me lo ha mandado, y que tomando la capa hizo como que venia a lo del señor correxidor y al pasar por la guardia de palacio se refugio a ella y dijo al aiudante vaia vuestra merced y digale al señor correxidor que aqui me quedo y que aora le avisare al señor precidente y que despues de todo esto se fue la declarante en compañia del referido aiudante para lo del señor Correxidor a contarle todo lo sucedido.

Preguntada que porque causa le dio las bofetadas el dicho miliciano y que personas havia delante $=$ Responde que havia alli varios pero que solamente conoce a uno nombrado Goyo, y que no dio mas merito que el que lleva declarado, y que es la verdad so cargo del juramento que fecho tiene y siendole leida esta su declaracion dijo ser la misma que hera de hedad de mas de veinte y ocho años y por no saver firmar hizo esta señal de cruz y lo firme = enmendado o entre renglones, i dile al Correxidor que te las quite valga $=$

\section{Blas Gonzalez"}

Declaración del ayudante Toribio Leiva. Santiago, 22 de mayo de 1775.

\section{[Al margen: "Declarazion de Torivio Leiba"]}

"Dicho dia mes y año comparecio ante mi Thorivio Leiba y tomandole el juramento en la forma acostumbrada para que dijesse la verdad en quanto supiesse y preguntado le fuese ofrecio decirlo = Preguntado que diga todo quanto paso con el miliciano Thadeo Idalgo quando fue a llamarlo esta noche de orden de su correxidor responde que haviendo ido a la casa de aquel a darle el recado de que se llegasse de orden del señor correxidor a lo de don Paulino Trais, le respondio el dicho miliciano, digale vuestra merced que aora no voy, mañana ire, ia se para lo que me quiere, ya e dado parte de todo a mi capitan, a lo que le replico el declarante vengase aora conmigo que esta es la orden que traigo y que tomando entonses la capa hizo como que obedecia, pero que al pasar por palacio se refugio a su guardia, y le dijo, digale vuestra merced al señor correxidor que aqui me quedo en lo de mi capitan y que iba a dar parte a su señoria y diciendole los soldados de dicha guardia vuestra merced no se canse que esto es como sagrado y que de alli no lo podia sacar, se retiro el declarante para lo de su correxidor a quien le dio parte de todo lo acaecido, que es quanto puede decir sobre lo dicho, y que es la verdad so cargo del juramento que fecho tiene y siendole leida esta su declarazion dijo era la misma y de hedad de unos treinta años poco mas o menos y que no savia firmar, e hizo la señal de la cruz $=$ 
Diligencia. Santiago, 22 de mayo de 1775.

"En el expresado dia mes y año yo el mencionado aiudante de la plaza don Blas Gonzalez pase las precedentes declaraciones al señor correxidor de esta ciudad don Luiz Sañartu de orden de mi Capitan General para los efectos que convengan y para que conste lo puse por diligencia y lo firme $=$

\section{Blas Gonzalez"}

Decreto del gobernador don Agustín de Jauregui. Santiago, 1 de junio de 1775.

"Santiago $1^{\circ}$ de junio de 1775.

En attencion a que con la pricion que ha sufrido Thadeo Hidalgo, soldado de la compañia de artilleros de esta ciudad, ha compurgado el desacato que cometio contra el actual corregidor de ella, se le ponga en libertad, y se le notifique se presentte al dicho corregidor y le satisfaga como corresponde; quedado adbertido este soldado y los demas de su clase, que siempre y quando las justicias ordinarias les mandasen llamar sin embargo del fuero que gosan, comparescan en sus jusgados con el respeto devido, $\mathrm{y}$ en ellos hagan las representaciones que les combenga $=$

Jauregui Traslaviña

\section{Borquez"}

Notificación. Santiago, 1 de junio de 1775.

[Al margen: "pagada"]

"En dicho dia mes y año notifique el decreto de suso al maestro Thadeo Idalgo de que doy fee $=$ 


\section{Ambrosio Guerrero, sastre, alférez de la compañía de artilleros contra don Nicolás Matorras por injurias. 1777.}

El alféres de la compañía de artillería Ambrosio Guerrero al gobernador de Chile don Agustín de Jaúregui. Santiago, 24 de mayo de 1777.

"Muy Ylustre Señor Presidente

El alferes de artilleros de las compañias urbanas de milicias de esta ciudad, puesto a los pies de vuestra señoria con su mayor rendimiento dice; que con motivo de estar siguiendo pleyto ante la justicia ordinaria como mayordomo de las cofradias de Nuestra Señora de Belem, y de las Nieves, contra doña Juana Gaete, sobre el derecho a unas varas de sitio, y de haver pasado a tomar posesion de ellas en virtud de lo juzgado a favor de dichas cofradias, a experimentado el suplicante los mayores ultrajes de don Nicolas Matorras, nieto de dicha doña Juana, tratandole con improperios, sin que para ello hubiese habido otro merito que el [de] defender el suplicante lo que p[or] tantos años se le ha tenido usu[rpa]do a las dichas cofradias: [res]pecto de ser notoria la vorasidad y altives del citado don Nicola[s] recelandose el suplicante que un dia pase a mayores insultos y [pro]vocaciones ocurre a la superior[i]dad de vuestra señoria a fin de que en atencion a lo expuesto y ha ser constante la honrades, juicio, y buena cond[ucta] de el que suplica, se sirva man$\mathrm{da}[\mathrm{r}]$ se notifique al expresado don N[ico]las se abstenga de tener atrabi[esa] la menor de obra, ni de palabra [con] el suplicante ni su familia ba[jo] la multa que fuese del supe[rior] arbitrio de Vuestra Señoria y de los aper[cibi]mientos correspondientes; a cuyo fin

A Vuestra Señoria pide y suplica se sirva proveer como lleva pedido, por ser assi de justicia costas y jura en lo necesario etc.

\section{Ambrosio Guerrero"}

Decreto. Santiago, 24 de mayo de 1777.

"Santiago y mayo 24 de 1777

Notifiquesele a don Nicolas Matorras se abstenga de tener atraviesa de obra ni de palavra con el suplicante, ni con su familia pena de cien pesos aplicados en la forma ordinaria

15 ANH CG, volumen 140, ff. 394-398 vta. 
Jauregui

Castro"

Doctor Lopez

Notificación. Santiago, 26 de mayo de 1777.

"En 26 de dicho notifique el [decreto] de la buelta a don Mathias de Matorras de que do[y] fe.

\section{Castro"}

Don Nicolás Matorras al gobernador de Chile don Agustín de Jaúregui. Santiago, 27 de mayo de 1777.

\section{Muy Ylustre Señor Presidente}

Don Nicolas Matorras vessino de esta ciudad, como mas haia lugar, paresco ante vuestra señoria y digo, que aier veinte y seis del corriente, se me hiso saber un superior decreto de vuestra señoria proveido, segun parese, a instancia de Ambrocio Guerrero, mulato sastre de esta ciudad, en que se me mandó notificar por vuestra señoria me astubiese de tener atrabiesa de obra, ni de palabra con el expresado mulato ni su familia, pena de cien pesos aplicados en la forma ordinaria.

Esta providencia, que ablando con mi maior respeto, me sorprendio vibamente por no contemplar en mi motivo para un apercivimiento tan eficas, me impelio naturalmemente a imponerme del pedimiento que la motivava: $Y$ haviendo conocido por su relacion que el principio de la queja, y providencia dada sobre hella, hera el lanse acaesido en el dia antecedente en precencia del señor alcalde ordinario de esta ciudad Agustin Tagle de la Cerda que con la autoridad de su actual empleo, paso a haser el deslinde que se relaciona en el memorial referido; yo no he podido ber sin admiracion el punto hasta donde ha llegado el atrevimiento de aquel sastre, que despues de haverme insultado al descuvierto, en precencia del jues mencionado, haia tenido audacia para quejarse en la superioridad de vuestra señoria y darse en hello por ofendido de un hecho en que usé de tanta moderacion, y por el que devió haver cido reprendido y castigado en el mismo.

Porque como lo informara a vuestra señoria el referi[do] señor alcalde, sin otro motivo que la regular contestacion que me fue presisa $\mathrm{a}=$ haser al tiempo de ejecutarse el desli[n]de que estaba practicando el señor alcalde, y no haverle trata- 


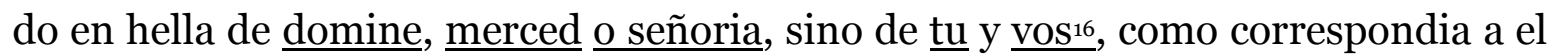
y a mi, se fulmino y abochorno de tal sue[rte] el desmedido engreimiento de este mulato, que empeso a he[char]me en cara, falta de crianza y educacion por el trata[miento] que le hacia, y aun no contento con la primera recombencion y mi respuesta sobre hella de no competirle otra cortesia, aument[o] de tal modo su desberguensa, que se vio nesecitada la umani[dad] y natural dulsura del alcalde a repremirlo con aspere[za] y mandar se separase de alli yncontinenti.

Esto que paso, como se ha dicho pressente ante el mismo alcalde y sobre que pido a vuestra señoria le mande informar [ex]presamente, ha cido todo el motivo de la queja de este sast[re] y sobre que ha recaido la providencia de vuestra señoria, tanto mas sencible [por] mi quanto parese por hella, haverse asentido en re[la]cion y que estimando en algo la delacion de un sugeto in[ileg.]me por derecho qual es todo un mulato por nuestras leies y [au]tores, se ha desantendido y olvidado las obligaciones que re[cae] en mi para ser moderado y tratar con un prudente [des]precio a hombres de la calidad de Guerrero principal[mente] estando yo como estaba tan sersiorado que su desberguen[za] havia causado ya de antemano muchos disgustos y pe[sa]dumbres a mi avuela doña Juana Gaete, contra quien [se] havia visto ya llegar hasta el punto de expresarle con modos y accion[es] que causa rubor expresarlas de boca de un yndividuo de [es]ta bajesa y oscuridad: Y lo que no es menor que en el mismo del deslinde faltava el respeto y atencion devida a la justicia no aquietandose con las determinaciones qu[e toma]ba y hacia en aquel mismo acto, sino protextando un[as] provocaciones, alsadas a que no podia [dar] lugar.

Por lo mismo y porque todo lo expuesto resultara del informe, que he pedido se mande haser al Alcalde e creido dever ocurrir a la superior justificacion de vuestra señoria para que en obsequio de la verdad y por desagravio del ultrage y sonrrojo que induce en mi perjuicio el pedimento referido se sirba mandar testarle y borrar, imponiendo al mismo tiempo a su autor la pena y apercevimiento que corresponde al desacato con que ceduciendo a esta superioridad y haciendo falsas y siniestras relaciones le ha faltado al respeto y atencion devida a su tribunal, y al decoro de mi persona; con las demas demostraciones que la superior justificacion de vuestra señoria estime combenientes a reprimir la insolencia del referido mulato; pues es un sugeto que tan en lo publico y con tanto desenfreno se atrebe a imponer falcedades y calumnias por escrito no se puede esperar en adelante si quedase impunido este desacato, sino que con maior libertad y abilantes proceda en otra ocacion a insultar con maior descaro a mi y a mi avuela y a quien se le ponga por delante, en perjuicio de la subordinacion y respeto con que los de su clase deven mi-

\footnotetext{
${ }^{16}$ Subrayados en el original.
} 
rar a los que son de otra superior segun las reglas de todo buen govierno = en cuia atencion.

A vuestra señoria suplico se sirba mandar que precediendo el imforme del alcalde que tengo pedido se difiera a la satisfaccion correspondiente que pido se me haga dar en este caso y a lo demas que la justificacion de vuestra señoria tenga por comveniente por ser todo de justicia que pido y en lo nessesario etc.

Nicolas de Matorras"

Decreto. Santiago, 27 de mayo de 1777.

"Santtiago y mayo 27 de 1777

Ynforme don Agustin de Tagle alcalde ordinario de es[ta] ciudad =

M. Jauregui

\section{Castro"}

Doctor Lopez

Informe del alcalde ordinario de Santiago don Agustín de Tagle. Santiago, 4 de junio de 1777 .

"Don Agustin de Tagle alcalde hordinario de esta ciudad paresco ante vuestra señoria y digo que conforme de lo mandado en el decreto de arriba, en que se $\mathrm{m}[\mathrm{e}]$ manda ynforme, sobre lo que acaecio el dia vein[te] y cinco del presentte, segun lo espuesto por don N[ico]las Matorras en su escrito: lo que debo informar a vuestra señoria es que aviendo presedido cierto acto [judicial] en casa de las Cofradias o seldas de Nuestra Señora de Belen, y de las Niebes, como partes interesadas la señora doña Juana Gaete, y Ambrocio Guerrero como maiordomo allandose presente tambien don Nicolas Matorras nieto de la antedicha doña Juana, presedieron sus disputas entre las partes sobre representar sus derechos, y afinadas esta oi: a lo ultimo estando algun trecho distante que dicho don Nicolas hablo de tu al citado Ambrocio y este le respondio que ci esa era su criansa que el no daba lugar para que se le tratase de esa suerte, aqui le contesto don Nicolas diciendole que le avia de ablar que ci cienpre no le avia ablado aci que cino era un perro mulato sastre, y conociendo que la disencion tomaria maior incremento, me bi conpelido a reprehender al citado Ambrocio, y mandarle que ci tenia alguna cosa que deducir sobre [lo] jusgado lo hiciese por escrito, y prociguiendo su controbercia, le hordene al citado Ambrocio se [re]tirase: es quanto en el asumpto puedo informar a vuestra señoria. Santiago y maio 31 de 1777.

Agustin Tagle de la Zerda” 
Decreto. Santiago, 4 de junio de 1777.

"Santiago 4 de junio de 1777.

Para probeer se ponga con este expediente el decretto que se citta -

- hay una firma -

Castro

Doctor Lopez"

Decreto. Santiago, 9 de junio de 1777.

“Santiago 9 de junio de 1777.

Testese la clausula rayada del memori[al] de Ambrocio Guerrero, y no se admita mas escrito en el asumpto $=$

Jauregui

\section{Castro"}

Doctor Lopez

Notificación. Santiago, 17 de junio de 1777.

Notificado a ambas partes en 17 de dicho $="$

Nicolás Escobar, cabo de la compañía de granaderos. Sobre disenso para casarse José Godoy, su sobrino, con Escolástica Ferreira, mulata. ${ }^{17}$ Santiago, 1787.

José Godoy al Alcalde de segundo voto como juez de primera instancia. Santiago, 7 de diciembre de 1787 .

"José Godoy comparese ante vuestra merced, con el mas sumiso rendimiento que debo y puedo digo: que me allo preso en esta carsel por orden de vuestra merced, del 28 del proximo mes pasado y por que quiero contraer matrimonio con Maria

${ }_{17}$ ANH, Fondo Real Audiencia, volumen 2903, pza $7^{\mathrm{a}}$, ff. 30-35 vta. 
Escolastica Ferreyra, haziendose las diliguencias que corresponden para mi estado prebengo a vuestra merced que despues de estar todo finalisado sale mi tio, Nicolas Gatica, por parte de mi señora madre, y ambos a dos padre, y madre, son muertos hi desde que me faltaron no e tenido mas amparo que solo mi diliguencia que a mi proseder hi onrades, hi no habiendo razon por donde me enbaraze mi espresado tio pues hasta qui no me ha hamparado en cosa alguna pues abiendolo nombrado para albazea de nosotros nos quito con grande ynjusticia parte de lo que nos tocaba hi siguio reconosiendo algun algun fabor o benefisio que por su mano me biniera le obedesiera en quanto me fuera posible y reconosiendo el desamor y poco amor que me tiene no es de razon que no estando debajo de su obediensia no puede por ningun modo sujetarme al estado que determino con la espresada a la buelta.

A Vuestra merced pido y suplico se sirba mandar como llebo pedido que es justicia costas etc.

A rruego del suplicante

\section{Rafael Flores"}

Nicolás Escobar, cabo de la compañía de granaderos, al alcalde de segundo voto. Santiago, 13 de diciembre de 1787.

"Nicolas Escovar, y Gatica cavo de la compañia de granaderos numeristas respondiendo al traslado de el pedimento de fojas 7 hecho a nombre de Josef Godoy mi sobrino digo: que justicia mediante se ha de servir la justificacion de usted negar en todo la solicitud de dicho mi sobrino atendiendo a las reales ordenes, y zedulas expedidas sobre el particular: lo primero, por que aunque dicho mi sobrino llevado de el antojo de cumplir su desenfrenado deseo en desdoro de toda su familia asienta que no esta sugeto a mi, ni a mis expenzas: razon que de ningun modo obsta, ni le aprovecha para el fin que solicita pero para que la integridad de usted bea lo falso de su aserto devo desir, que habra cosa de diez años que faltaron los padres de el susso dicho desde cuio tiempo lo he tenido en mi compañia, y aun fiandome de el en la administracion de mis ventas de las que ha usado con bastante dolo, y engaño: Asi mismo asienta en el referido su pedimento que yo como albacea de sus padres le disipe sus vienes, y tan ignorante esta en uno como en otro casso; pues yo fui solo apoderado por parte de su abuelo para recaudar los vienes que les havian quedado de sus padres; $y$ no albacea como dice.

Pero lo mas lamentable es señor que siendo mi sobrino un muchacho español que apenas tiene beinte años cumplidos, quiera contraer matrimonio con una mulata muger publicamente desonesta, pues ha tenido barios hijos sin ser casada; $y$ que por razon de su hedad puede ser descansadamente su madre y resultando de sus diferencias las ningunas abeniencias entre los casados que se experimentan; 
ante si mil disturbios, y disenciones; por todo lo qual se ha de servir la justificacion de usted negar toda la solicitud de dicho mi sobrino, pues las cauzas son tan notoriamente justas, y evidentes; que en casso nesesario estoy pronto a provarlas. Por tanto.

A usted pido y supplico se sirva decretar en todo segun, y como llevo pedido que es justicia. Costas etc.

Nicolas Escovar.”

Auto. Santiago, 13 de diciembre de 1787.

"Santiago y diziembre 13 de 1787.

Esta parte justifique en debida forma la relacion que hace en este escrito con citacion de Joseph Godoy y fecho autos.

Aldunate

Borquez.”

Probanza de Nicolás Escobar. Santiago, 10 de enero de 1788.

"Nicolas Escobar y Gatica en la mejor forma que haia lugar en derecho paresco ante usted y digo: que para provar el derecho que me compete sobre impedir el matrimonio que intenta obtener Josef Godoy mi sobrino, se ha de servir la justificacion de usted mandar que los testigos que produgere sean examinados al tenor de las preguntas de el interrogatorio siguiente

$1^{\mathrm{a}}$. Primeramente por el conocimiento de las partes noticia de la cauza, y generales de la ley digan

$2^{\mathrm{a}}$. Ytem si saven que el referido Jose Godoy es hijo legitimo de legitimo matrimonio de Estevan Godoy y de Ursula Suares; y si estos fueron tenidos siempre por personas españolas, limpias de toda mala raza de negros y mulatos, digan

$3^{\text {a }}$ Yten si saven, que despues de el fallecimiento de los padres de el citado Josef ha estado siempre a mi abrigo, y amparo corriendo con mis - ileg. - negociaciones ileg. -

$4^{\mathrm{a}}$. Yten si saven que Escolastica Ferreyra es hija de Santos Ferreyra sambo atezado que tira a negra, y de una yndia; cuio nombre expresaran si lo tubieren presente, y en lo que no se remitiran a lo publico de ello digan etc

$5^{\mathrm{a}}$. Yten si saven, que la citada Escolastica es muger mundana, y que si a consecuencia de esto saven que ha tenido barios hijos sin ser casada, de diferentes padres, digan etc 
$6^{\mathrm{a}}$. Si saven, que su exercicio de esta ha cido siempre el de pulpera, y de las que llaman comunmente rateras, o de el gato rebendiendo en la plaza digan etc $7^{\mathrm{a}}$. Yten de publico, $\mathrm{y}$ notorio publica bos, $\mathrm{y}$ fama digan etc $=$ por tanto $=$ A usted pido y suplico, que haviendo por presentado el ynterrogatorio se sirva mandar que los testigos que produgere sean examinados al tenor de sus preguntas etc.

Nicolas Escovar.”

Decreto del alcalde ordinario de Santiago don Juan Francisco de Santa Cruz. Santiago, 10 de enero de 1788.

"Santiago y enero 10 de 1788

Por pasados los autos en el dia; y en atenzion a tenerse noticias de que Escolastica Ferreira se halla actualmente en la Casa de Recogidas; y Jose Godoi ausente de esta ciudad, y no se su paradero: Por aora entretanto se aberigua. Hagasele saber que teniendo casa de satisfaccion a la qual pueda salir lo que hara constar por papel del dueño y padre de familia della se le conzede esta gracia en virtud de la qual la rectora de la de Recogidas no le embarasara su salida: y el actuario reserbara los autos para que a su tiempo se de providencia de el matrimonio que se dice desean contraer.

Santa Cruz.” 